\title{
Heterochromatin-Like Regions as Ecological Niches for Avirulence Genes in the Leptosphaeria maculans Genome: Map-Based Cloning of AvrLm6
}

\author{
I. Fudal, ${ }^{1}$ S. Ross, ${ }^{1}$ L. Gout, ${ }^{1,2}$ F. Blaise, ${ }^{1}$ M. L. Kuhn, ${ }^{1}$ M. R. Eckert, ${ }^{1}$ L. Cattolico, ${ }^{3}$ S. Bernard-Samain, ${ }^{3}$ \\ M. H. Balesdent, ${ }^{1}$ and T. Rouxel ${ }^{1}$ \\ ${ }^{1}$ Phytopathologie et méthodologies de la détection, INRA, F-78026 Versailles, France; ${ }^{2}$ Protection des Plantes, INA P-G, \\ F-78850 Thiverval-Grignon, France; ${ }^{3}$ Genoscope-Centre National de Séquençage, 91057 Evry Cedex, France
}

Submitted 15 September 2006. Accepted 17 October 2006.

\begin{abstract}
Map-based cloning of avirulence genes of the AvrLm1-2-6 cluster was recently undertaken in Leptosphaeria maculans and led to the identification of AvrLm1. The ensuing chromosome walk toward AvrLm6 resulted in the delineation of a 562-kb bacterial artificial chromosome (BAC) clone contig in an avirulent isolate. Following sequencing of the contig and sequence comparison with a virulent isolate, four AvrLm6 candidate genes were identified. Complementation of the virulent isolate with the four candidates was performed and one gene was found to fully restore the avirulent phenotype on Rlm6 oilseed rape genotypes. AvrLm6 was found to be located in the same genome context as AvrLm1, because it is a solo gene surrounded by 85 and $48 \mathrm{~kb}$ of degenerated repeats on its $5^{\prime}$ and $3^{\prime}$ sides, respectively. AvrLm6 is an orphan gene encoding a small, potentially secreted, cysteine-rich protein. Comparison of AvrLm1 and AvrLm6 expressions by quantitative reverse-transcription polymerase chain reaction revealed that both genes are highly overexpressed during primary leaf infection. Using RNA interference, decreasing expression of AvrLm6 was shown to result in virulence toward $R \operatorname{lm} 6$ genotypes whenever the expression was reduced by more than $60 \%$ compared with the wild-type isolate.
\end{abstract}

Additional keywords: Brassica napus, stem canker.

Plants have developed specific defense mechanisms against microbial pathogens. These defense responses include a rapid localized cell death termed hypersensitive response (HR) that will stop pathogen infection (Hammond-Kosack and Parker 2003). These plant defense responses often are triggered by a specific recognition event that is controlled by a plant resistance gene $(R)$ and a pathogen avirulence gene $(A v r)$ as proposed in

Corresponding author: Thierry Rouxel; E-mail: rouxel@versailles.inra.fr

I. Fudal and S. Ross contributed equally to this work.

Nucleotide sequence data is available in EMBL databases under accession numbers AM259336 (AvrLm6), CT485790 (BAC 138E11), CT485668 (BAC 24A10), CT485649 (BAC 64D2), CT485653 (BAC 52C10), CT485669 (BAC 20H11), CT485664 (BAC 33B11), CT485651 (BAC 56B7), CT485648 (BAC 6G9), CT485647 (BAC 6H1), and CT485673 (BAC 115B5)

* The $e$-Xtra logo stands for "electronic extra" and indicates the HTML abstract available online contains supplemental material not included in the print edition. Two supplemental tables appear online. the gene-for-gene model (Flor 1971). Avr genes encode either proteins that are recognized by resistant plants involving directly or indirectly the corresponding resistance gene product, or enzymes involved in production of molecules that are recognized by resistant plants (Keen 1990; Van Der Biezen and Jones 1998). Only a few Avr genes from fungal plant pathogens have been identified and they were restricted to seven fungal species: the Dothideomycetes Cladosporium fulvum (Joosten et al. 1994; Luderer et al. 2002; van Kan et al. 1991; Westerink et al. 2004) and Leptosphaeria maculans (Gout et al. 2006), the Leotiomycetes Rhynchosporium secalis (Rohe et al. 1995) and Blumeria graminis f. sp. hordei (Ridout et al. 2006), the Sordariomycetes Magnaporthe grisea (Böhnert et al. 2004; Farman et al. 2002; Orbach et al. 2000) and Fusarium oxysporum (Rep et al. 2004), and the Basidiomycete Melampsora lini (Catanzariti et al. 2006; Dodds et al. 2004). The majority of the Avr proteins are small and cysteine rich, without homology to each other, and are known or expected to be secreted into the host plant tissues during infection (Rep 2005). Predicting intrinsic function for the proteins encoded by fungal $A v r$ genes has proven difficult. NIPl from the barley pathogen $R$. secalis encodes a peptidic toxin that induces necrotic lesions (Rohe et al. 1995). Avr4 from $C$. fulvum is a chitin-binding protein that protects fungal cell walls from degradation by plant chitinases, and Avr2 is an inhibitor of the extracellular cysteine protease Rcr3 in tomato (Rivas and Thomas 2005). Last, in Melampsora lini, AvrP123-A contains a sequence characteristic of Kazal Ser protease inhibitors, suggesting a possible role in inhibition of host protease, and AvrP4 contains a Cys-knot structure similar to that found in some inhibitors of receptors or proteases (Catanzariti et al. 2006). These data concur to suggest that fungal $A v r$ genes are actually "effectors" (i.e., pathogen molecules that manipulate the host cells, thereby evading plant recognition or facilitating infection on susceptible genotypes, as shown for bacterial and oomycete $A v r$ genes) (Chisholm et al. 2006; Kamoun 2006; Mudgett 2005).

The lack of homology of Avr genes at the amino-acid level, along with the development of whole-genome initiatives in plant pathogens, allows us to examine the role, acquisition, and evolution of these Avr determinants (Birch et al. 2006). To address these questions in filamentous fungi, there is a need to focus primarily on those species for which more than one Avr gene has been cloned or tightly mapped and for which wholegenome sequence is available or will shortly become available. In $M$. grisea, three $A v r$ genes were located at different places in the genome, AVR-Pita being located close to a telomere (Orbach et al. 2000) while other genes identified had no par- 
ticular localization (Böhnert et al. 2004; Farman et al. 2002). Those genes were not clustered and they encoded proteins with different structures, from small secreted proteins to a large multifunctional enzyme (Böhnert et al. 2004). Four Avr genes were identified in $C$. fulvum and were found to encode small, cysteine-rich secreted proteins (Rivas and Thomas 2005). However, no information is available about their localization and possible clustering in the genome, because they were identified by reverse genetics after screening of apoplastic fluids or by functional screening using a binary PVX vector, and $C$. fulvum is not amenable to formal genetic studies. The four Avr genes recently identified in Melampsora lini were expressed in haustoria and encoded small secreted proteins, of which AvrP123-A and AvrP4 are cysteine rich and probably act as effectors (Catanzariti et al. 2006; Dodds et al. 2004). No information is available about their clustering and localization in the genome. Finally, the two Avr genes recently identified in B. graminis f. sp. hordei $\left(A V R_{a 10}\right.$ and $\left.A V R_{k l}\right)$ encoded small proteins that lack secretion signal peptides and enhance infection success on susceptible host plant cells. $A V R_{a 10}$ and $A V R_{k l}$ belonged to a genetic cluster of avirulence genes linked by 1 to $2 \mathrm{cM}$ and were separated by $7.5 \mathrm{~kb}$. These genes were found to belong to a large family of more than 30 paralogs in the genome of B. graminis f. sp. hordei (Ridout et al. 2006). Overall, apart from M. grisea, B. graminis f. sp. hor$d e i$, and distantly related oomycete species, little is known about the genomic context in which Avr genes are located.

L. maculans, the Dothideomycete causing stem canker of oilseed rape, is an emerging model to analyze genomic distribution and evolution of $A v r$ genes within a genome. Indeed, formal genetic studies evidenced genetic clustering of $A v r$ genes in the fungal genome (Balesdent et al. 2002), and the cloning of one gene of such a genetic cluster, AvrLml, recently was performed following the sequencing of a large genomic region encompassing the gene (Gout et al. 2006). AvrLml was found to be physically isolated from housekeeping genes in the middle of a large heterochromatin-like region. Although AvrLm1 shared common features with other Avr proteins (presence of a cleavable signal peptide, small size, and lack of sequence homology in databases), it also had specific features, including a scarce number of cysteine residues, suggesting a short life duration in plant apoplast (Gout et al. 2006). The cloning of AvrLml further questioned the genomic significance of genetic clustering of $A v r$ genes in the L. maculans genome and whether the structural characteristics of the AvrLml environment are specific to AvrLml or the rule for L. maculans Avr genes.

To address these questions, we present here the cloning, functional characterization, and analysis of the genome environment of a second Avr gene of the AvrLm1-2-6 cluster, AvrLm6. Following positional cloning of AvrLm1, detailed genetic and physical maps of the AvrLm6 locus were constructed. Complete sequencing of the corresponding 520-kb contig allowed identification of several AvrLm6 candidate genes, of which one was validated through complementation assays. AvrLm6 structure, genomic location, and expression using quantitative reverse-transcription polymerase chain reaction (qRT-PCR) were analyzed and compared with that of AvrLm1. The AvrLm6 / Rlm6 interaction was further analyzed by using RNAi in order to silence AvrLm6 expression.

\section{RESULTS}

Construction of a BAC contig covering the AvrLm6 locus of the v23.1.3 avirulent isolate.

Contig assembly started from Vir2, a Pholy-based PCR marker (Rep-PCR) (Attard et al. 2005, Gout et al. 2006), which cosegregated with AvrLm6. This Rep-PCR marker al- lowed the identification of two bacterial artificial chromosome (BAC) clones, 56B7 and 6G9. BAC end sequences of 6G9 did not allow identification of a new marker, whereas end sequencing of BamHI-digested subclones allowed us to design the 6G9Bam marker (Fig. 1). The BAC clone $6 \mathrm{H} 1$ then was identified and marker $6 H 1 F$ was designed after BAC end sequencing. Finally, 115B5 was identified and found to contain a marker genetically bordering the AvrLm6 locus on its 3' side (micPKS) (Fig. 1). In the $5^{\prime}$ end of BAC clone 56B7, the AvrLm6 contig was extended by the same method, generating markers after sequencing of BAC ends or after subcloning of the BAC clones. Two new BAC clones were identified: 33B11 and 20H11. During the map-based cloning of AvrLml, Gout and associates (2006) defined a contig where the BAC located at the $3^{\prime}$ end, 24A10, contained a marker that cosegregated with AvrLm6. The contig was extended from 24A10 with marker $24 A 10 F$ and allowed identification of 64D2. After the whole contig extension, a gap was still present between 64D2 and $20 \mathrm{H} 11$. This gap was filled after complete sequencing of $20 \mathrm{H} 11$ by Genoscope. From this sequence, a new marker, 20H11, was designed and allowed identification of a BAC clone bridging the gap. The final AvrLm6-contig consisted of 10 overlapping clones covering a distance of 565,321 bp (Fig. 1). Full sequencing of the 10 BAC clones was performed. Additional markers were designed from the AvrLm6-contig sequence to saturate the genetic map of the AvrLm6 locus (Fig. 1).

\section{Genetic mapping of the AvrLm6 locus and characterization of the AvrLm6 contig.}

The AvrLm6 gene was mapped in a 14.8-centimorgan (cM) interval between the two flanking markers mic2601 $(6 \mathrm{cM}$ on the $5^{\prime}$ side) (Gout et al. 2006) and micPKS (8.8 cM on the $3^{\prime}$ side) that delineated a 520-kb interval, giving an average physical-to-genetic-distance ratio of $35.1 \mathrm{~kb} / \mathrm{cM}$ (Fig. 1). However, no recombination events were identified between 12 markers located along this genetic interval and corresponding to a physical distance of $458 \mathrm{~kb}$ (Fig. 1). This indicates that recombination was highly suppressed in the region encompassing AvrLm6 and that equivalence between physical and genetic distance was variable in the region.

A total of 21 genes were predicted within the AvrLm6 genetic interval (Fig. 1) (Supplementary Table S1). Based on homology to other genes or protein domains deposited in databases, 12 genes present in the AvrLm6-contig could be assigned putative functions and 7 genes showed homologies with conserved hypothetical fungal proteins (Supplementary Table $\mathrm{S} 1$ ). These genes mainly were distributed among three generich regions, termed GC2 (20.7 kb), GC3 (21.7 kb), and GC4 $(22.3 \mathrm{~kb})$, characterized by an average $51.28 \%$ GC content and absence of retrotransposons. Sequences located between these gene-rich regions, namely REP3 (15 kb) and REP4 (453.3 kb), were characterized by a low GC content (average $34.91 \%$ ). The REP regions mainly contained the four LTR retrotransposons Pholy, Olly, Polly, and Rolly (Gout et al. 2006; data not shown). Even if some complete copies of the four LTR retrotransposons were identified in the $520-\mathrm{kb}$ contig, they generally appeared to be truncated at one or both termini or occurred as solo LTRs (data not shown). Sequences of the different retrotransposons identified were highly degenerated as a result of extensive repeat-induced point mutations (data not shown) as previously reported (Attard et al. 2005; Gout et al. 2006). The REP regions included six predicted genes, isolated in the region as solo genes or in couples (Fig. 1).

\section{Identification of AvrLm6 candidate genes.}

Within the 520-kb interval, the best AvrLm6 candidate among the 21 predicted genes was difficult to select due to 
strong suppression of genetic recombination (Fig. 1). RT-PCR experiments on RNA extracted from plants infected with either the avirulent isolate v23.1.3 or the virulent isolate v29.3.1 showed expression of 19 of the predicted genes in both isolates, whereas two genes located in the REP4 region ( LmCys 2 and LmCys3 (Fig. 1) (Supplementary Table S1) were detected only in the avirulent isolate. In addition, analysis of genomic DNA in two AvrLm6 isolates (v23.1.3 and Nz-T4) and one avrLm6 isolate (v29.3.1) indicated that five genes were polymorphic between the avirulent and the virulent isolates. $L m P K S, L m C y s 1$, and $L m M F S$ showed nucleotidic polymorphism among v23.1.3, Nz-T4, and v29.3.1, whereas LmCys2 and $L m C y s 3$ were absent in the virulent isolate v29.3.1. Those five genes were primarily considered as possible candidates for AvrLm6, but LmPKS finally was ruled out due to the presence of the micPKS marker in this gene. The four remaining AvrLm6 candidate genes were located in the REP4 genomic region.
Identification of AvrLm6 by functional complementation.

To test the ability of the four AvrLm6 candidate genes to confer avirulence toward cultivars carrying $R \operatorname{lm} 6$, complementation assays were carried out. Genomic fragments of v23.1.3 corresponding to the coding region and putative promoter of the four candidate genes were cloned in the binary vector pBHt 2 and introduced into the virulent isolate v29.3.1 by Agrobacterium-mediated transformation. Overall, 17 independent transformants were isolated for $\mathrm{pBHt} 2-\operatorname{LmCys} 1,12$ transformants for $\mathrm{pBHt} 2-\mathrm{LmCys} 2,16$ transformants for $\mathrm{pBHt} 2-\mathrm{LmCys} 3$, and seven transformants for $\mathrm{pBHt} 2-L m M F S$. These transformants then were inoculated on two Brassica napus lines carrying Rlm6, Darmor-MX, and Falcon-MX (Table 1). V29.3.1 transformants carrying pBHt2-LmCys1, pBHt2-LmCys2, or pBHt2-LmMFS constructs exhibited the same phenotype as the wild-type recipient (Table 1). In contrast, transformation of pBHt2-LmCys3 into v29.3.1 fully restored the avirulent interaction phenotype with Darmor-MX and Falcon-MX for 14 of

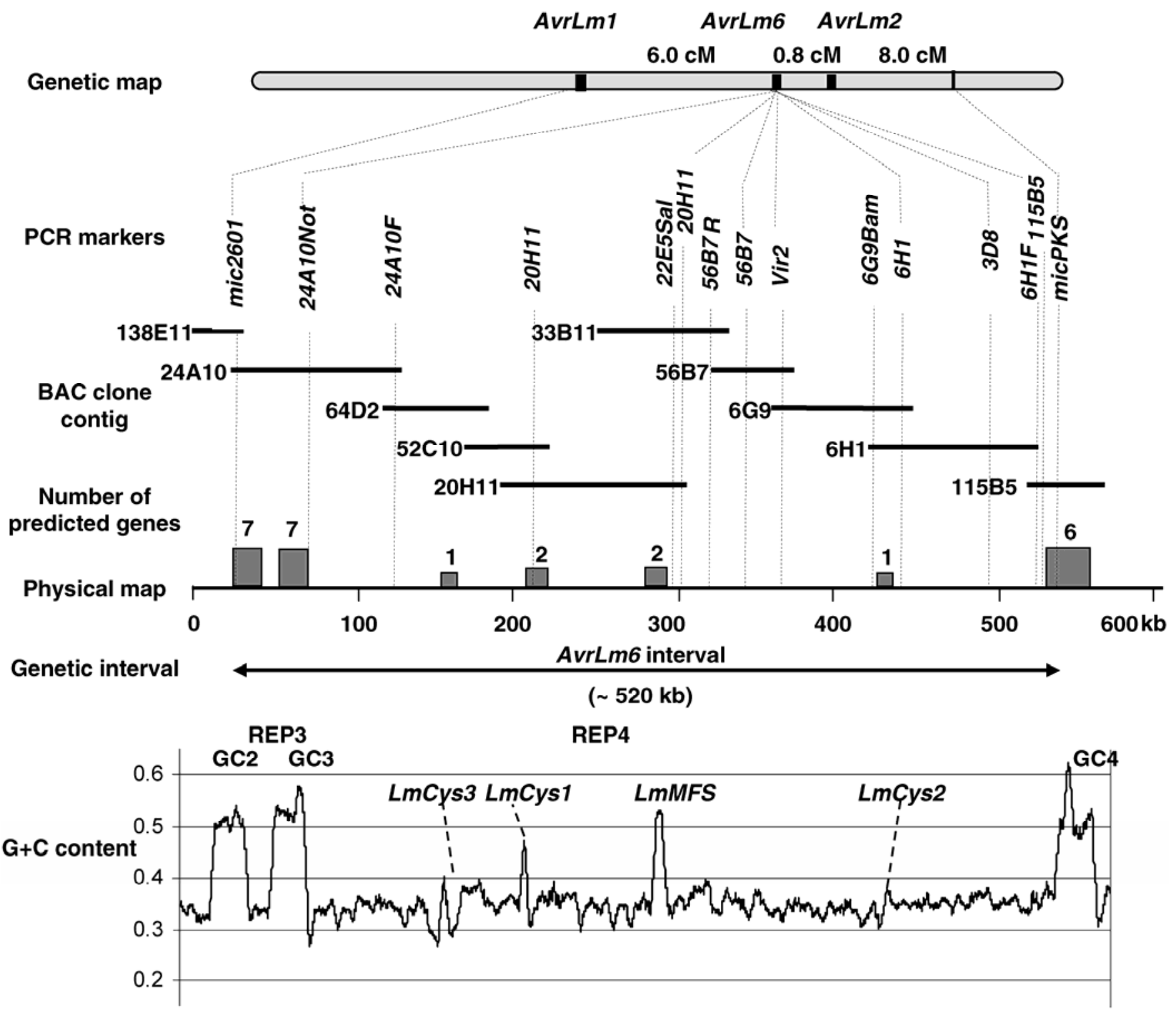

Fig. 1. Genetic and physical maps of the AvrLm6 genomic region in the v23.1.3 (AvrLm6) isolate. Genetic and physical maps: dashed lines connect the physical location of markers to their location on the genetic map or connect markers to their location in the bacterial artificial chromosome (BAC) clone contig. Genes were predicted according to gene-prediction programs FGENESH and GENSCAN. The double-arrow corresponds to the AvrLm6 genetic interval and shows the region spanning the AvrLm6 locus. G+C content: sliding window (size 3,500 bp, step $100 \mathrm{bp}$ ) analysis of the $\mathrm{G}+\mathrm{C}$ content in the $565 \mathrm{~kb}-\mathrm{con}-$ tig. Regions REPx and GCx correspond to regions with homogeneous G+C content. LmCys1, LmCys2, LmCys3, and LmMFS are the genes identified as candidates for AvrLm6 and used for complementation assays. PCR = polymerase chain reaction. 
16 transformants (Table 1). The v29.3.1/pBHt2-LmCys3 transformants showed a wild-type interaction phenotype with the susceptible cultivar (Table 1) and with the cultivars carrying either Rlm1 or Rlm2 (Table 1). Thus, LmCys3, a solo gene located in REP4, was suggested to be AvrLm6.

\section{Sequence analysis and occurrence of the AvrLm6 gene in Leptosphaeria spp.}

The 3,405-bp PCR product amplified from v23.1.3 with primers 64D2-smaU and 64D2-smaL and used for functional complementation of the AvrLm6 avirulence phenotype contained a single predicted open reading frame (ORF). AvrLm6 cDNA was synthesized from v23.1.3 total RNA by RT-PCR and used to determine the position of the different introns. Three introns of 51, 47, and 48 bp were identified (Fig. 2). RACE PCRs ( $5^{\prime}$ and $3^{\prime}$ ) were performed on v23.1.3 cDNA to localize the transcription initiation and polyadenylation sites. Two independent protocols were used to perform $5^{\prime}$ and $3^{\prime}$ RACE PCRs, which gave the same results, a $5^{\prime}$ untranscribed region (UTR) of $58 \mathrm{bp}$ and a $3^{\prime}$ UTR of $178 \mathrm{bp}$ (Fig. 2). The AvrLm6 transcript was 817 bp in size and with a low GC content $(43 \%)$, similar to the average GC content of the genomic context (Fig. 1). A 435-bp ORF was predicted within the transcript and encoded a predicted preprotein of 144 amino acids (aa), which included a potential 20 -aa cleavable signal peptide (signal peptide probability of 0.982 with SignalP 3.0 software), suggesting that it encodes a secreted protein of 124 aa and $13.4 \mathrm{kDa}$. The predicted AvrLm6 protein contained six cysteine residues (Fig. 2) and two disulphide bonds were predicted using the SCRATCH software (amino acid positions 109 to 130 and 103 to 122 ). No particular structure, localization, or amino acid composition was found using PSortII and SAPS softwares.

No significant matches to the public DNA sequence databases and to the sequenced fungal genomes were detected and no homology with AvrLml identified. Similarly, the predicted AvrLm6 protein had no similarity to protein families deposited in the Pfam database. Moreover, no significant matches to sequences of the closely related species Stagonospora nodorum (Phaeosphaeria nodorum) were identified, whereas microsynteny is observed between $L$. maculans and $S$. nodorum for other genes of the AvrLm6 genomic region (Supplementary Table S1). Presence of AvrLm6 homologs was investigated by PCR and by Southern blot hybridization using the AvrLm6

Table 1. Complementation assays with the AvrLm6 candidate genes: pathogenicity of the v29.3.1 transformants

\begin{tabular}{|c|c|c|c|c|c|}
\hline \multirow[b]{2}{*}{ Isolate/transformant } & \multicolumn{5}{|c|}{ Pathogenicity test on ${ }^{\mathrm{a}}$} \\
\hline & $\begin{array}{l}\text { Westar (susceptible } \\
\text { control) }\end{array}$ & $\begin{array}{c}\text { Falcon-MX } \\
(R \operatorname{lm} 4 \text { Rlm6) }\end{array}$ & $\begin{array}{l}\text { Darmor-MX } \\
\quad(R \operatorname{lm} \sigma)\end{array}$ & $\begin{array}{c}\text { Bristol }(R \operatorname{lm} 2 \\
\quad R \operatorname{lm} 9)\end{array}$ & $\begin{array}{c}\text { Columbus } \\
(R \operatorname{lm} 1 R \operatorname{lm} 3)\end{array}$ \\
\hline v23.1.3 (AvrLm1avrLm2AvrLm6) & $\mathrm{V}$ & A & A & $\mathrm{V}$ & A \\
\hline v29.3.1 (avrLm1AvrLm2avrLm6) & $\mathrm{V}$ & $\mathrm{V}$ & $\mathrm{V}$ & A & $\mathrm{V}$ \\
\hline $\mathrm{v} 29.3 .1 / \mathrm{pBHt} 2 / \mathrm{LmCys} I^{\mathrm{b}}$ & $\mathrm{V}$ & $\mathrm{V}$ & $\mathrm{V}$ & A & $\mathrm{V}$ \\
\hline $\mathrm{v} 29.3 .1 / \mathrm{pBHt} 2 / \operatorname{LmCys} 2^{\mathrm{b}}$ & $\mathrm{V}$ & $\mathrm{V}$ & $\mathrm{V}$ & A & $\mathrm{V}$ \\
\hline $\mathrm{v} 29.3 .1 / \mathrm{pBHt} 2 / \operatorname{Lm} C y s 3^{\mathrm{b}}$ (transformants $1-6,8$, and $\left.10-16\right)$ & $\mathrm{V}$ & A & A & A & $\mathrm{V}$ \\
\hline $\mathrm{v} 29.3 .1 / \mathrm{pBHt} 2 / \operatorname{LmCys} 3^{\mathrm{b}}$ (transformants 7 and 9 ) & $\mathrm{V}$ & $\mathrm{V}$ & $\mathrm{V}$ & A & $\mathrm{V}$ \\
\hline $\mathrm{v} 29.3 .1 / \mathrm{pBHt} 2 / L m M F S^{\mathrm{b}}$ & $\mathrm{V}$ & $\mathrm{V}$ & $\mathrm{V}$ & A & $\mathrm{V}$ \\
\hline
\end{tabular}

${ }^{a}$ Conidia were inoculated onto cotyledons of 15-day-old plantlets of reference cultivars carrying known resistance genes (Balesdent et al., 2005). The symptoms were scored 15 days postinfection as the isolate is avirulent $(\mathrm{A})$ or virulent $(\mathrm{V})$.

${ }^{\mathrm{b}} \operatorname{LmCys} 1, \operatorname{LmCys} 2, \operatorname{LmCys} 3$, and $L m M F S$ were amplified by polymerase chain reaction from v23.1.3 and cloned into the pBHt2 binary vector. Constructs were introduced into v29.3.1 by Agrobacterium-mediated transformation.

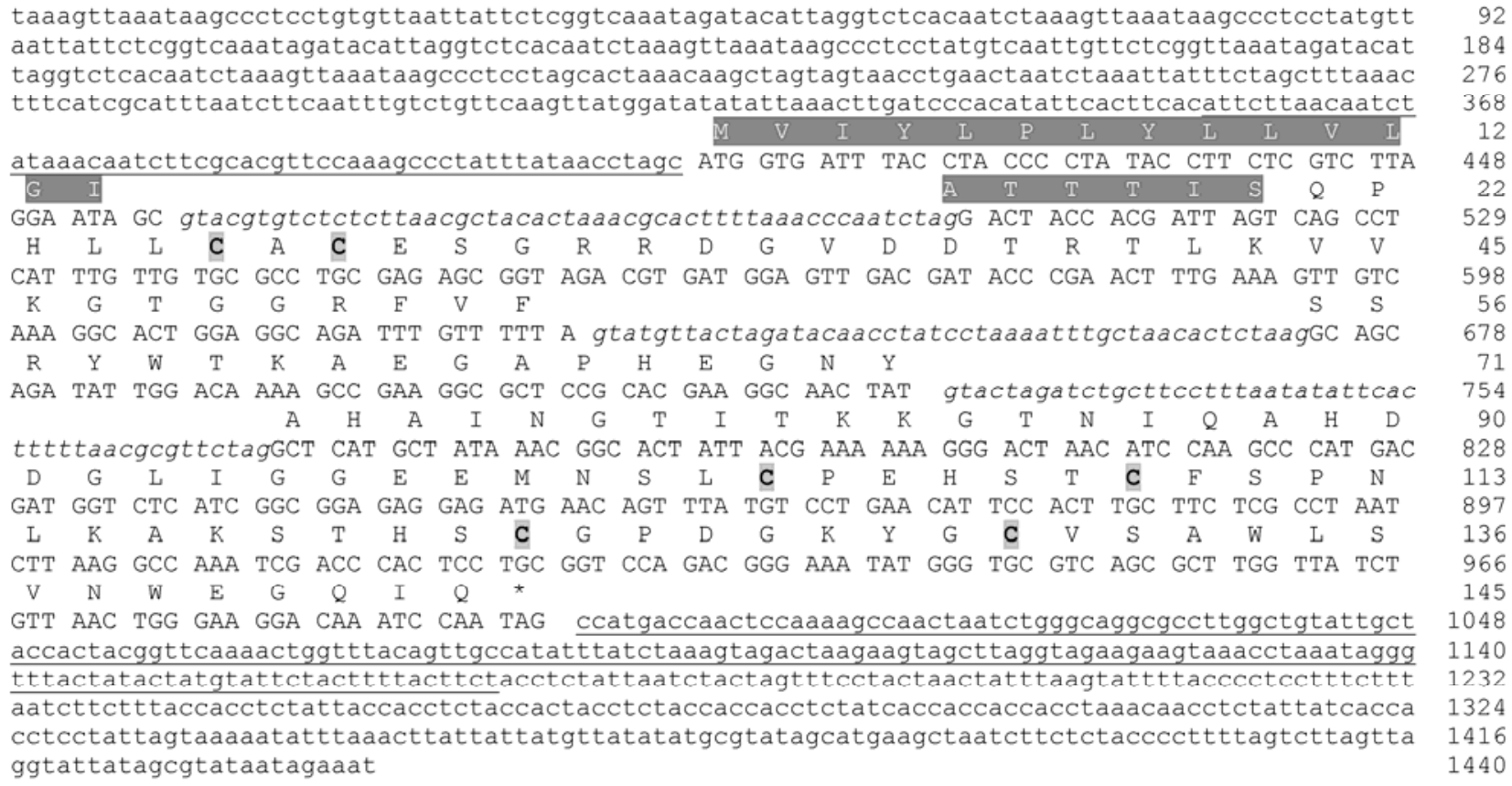

Fig. 2. Nucleotidic sequence of the 1,440-nucleotide (nt) region encoding AvrLm6 (accession number AM259336) and amino acid sequence of the corresponding predicted protein. $5^{\prime}$ and $3^{\prime}$ untranslated regions of the gene are underlined. Introns are indicated as italicized lowercase (intron 1: $51 \mathrm{nt}$; intron 2: $47 \mathrm{nt}$; and intron 3: $48 \mathrm{nt}$ ). The predicted signal peptide ( 20 amino acids) is indicated by dark gray shading and the six cysteine residues are indicated by gray shading. 
ORF as a probe in isolates from other species or subspecies of the L. maculans $-L$. biglobosa species complex (Table 2). The gene was absent from all subspecies of L. biglobosa and even of the closely related $L$. maculans subspecies 'lepidii', suggesting that it is extremely specific to the L. maculans subspecies infecting Brassica spp. (L. maculans 'brassicae').

\section{Comparison of AvrLm6 and AvrLm1 expression.}

AvrLm1 expression was investigated using RT-PCR (Gout et al. 2006) and found to be expressed at some level in all stages with a probable induced expression during primary leaf infection. Here, we developed a more precise analysis of the expression of AvrLm1 and AvrLm6 using qRT-PCR. Primer efficiency was calculated for AvrLm1, AvrLm6, $\beta$-tubulin, and actin and was found to range between 0.992 and 1 . Gene expression levels of AvrLm1 and AvrLm6 were measured relative to $\beta$-tubulin expression (Fig. 3). Gene expression level of actin also was measured relative to $\beta$-tubulin and showed no significant variations among the different in planta and in vitro conditions (Fig. 3), indicating that $\beta$-tubulin and actin are adequate constitutive reference genes. AvrLm6 expression was detected at a low level 3 days postinfection (dpi), then increased during the primary leaf infection and peaked at 7 dpi $(13,190$ times more expressed than in conidia germinating in rich medium). At this time, AvrLm6 was even more expressed than $\beta$-tubulin (Fig. 3). Expression of AvrLm6 slowly decreased after 7 dpi and, during stem necrosis, it was comparable to the expression exhibited 5 dpi. AvrLm6 expression was also faintly detected in mycelium and at lower levels in conidia germinating in complete medium and under nitrogen starvation, suggesting that nitrogen starvation did not increase the level of AvrLm6 expression. Expression kinetics of AvrLm1 was very similar to that of AvrLm6: AvrLm1 was also strongly expressed during primary leaf infection with a peak at 7 dpi $(2,100$ times higher than in conidia germinating in rich medium). Contrasting with AvrLm6, and as already shown by RT-PCR, the level of AvrLml expression during mycelial growth was high (21.5 times higher than that of AvrLm6) (Fig. 3).

\section{Characterization of the AvrLm6-RIm6 interaction following RNA silencing of AvrLm6.}

RNAi had already been used successfully in fungi such as Venturia inaequalis and M. grisea (Fitzgerald et al. 2004; Nakayashiki et al. 2005) and was adapted for L. maculans (this study) (Fig. 4). We constructed a vector (pNAT1-AvrLm6) containing a fragment of AvrLm6 cDNA in sense and antisense orientation, in order to allow hairpin formation when transcribed into mRNA. pNAT1-AvrLm6 then was transformed into v23.1.3 (AvrLm6) by agrotransformation. Eighteen transformants were obtained and analyzed for their ability to infect Darmor-MX (Fig. 5) and for the level of AvrLm6 expression, using qRT-PCR (Fig. 4). Four transformants showed an expression level as low as 3.5 to $13 \%$ of the wild-type control (Fig. 4, transformants 3, 13, 16. and 17). Statistical analyses showed that Westar developed similar symptoms when inoculated with v23.1.3 or all but one of the silenced transformants (transformant 1) (data not shown). The four nonsilenced transformants $(10,15,18$, and 19) never induced susceptibility symptoms on Rlm6 and behaved like v23.1.3 (data not shown). In contrast, although v23.1.3 was avirulent, most of the silenced transformants induced susceptibility symptoms on the Rlm6 line $21 \mathrm{dpi}$ (Fig. 5B). The four silenced transformants exhibiting the lowest level of AvrLm6 expression (less than 15\%) were found to be fully virulent toward $R \operatorname{lm} 6$, with a high percentage of susceptibility symptoms already detected 14 dpi (Fig. 5A). Transformants with intermediate expression of AvrLm6 (transformants 1, 9, 11, 12 and 20) showed some susceptibility symptoms; however, those symptoms were delayed and mainly appeared $21 \mathrm{dpi}$. Correlation curves further showed linear relationships between symptom expression on Rlm6 cultivars and AvrLm6 expression level (Fig. 5).

\section{DISCUSSION}

In a recent article, Gout and associates (2006) reported the cloning of a first Avr gene from L. maculans, AvrLm1. AvrLm1, belonging to the AvrLm1-AvrLm2-AvrLm6 genetic cluster

Table 2. Occurrence of AvrLm6 in Leptosphaeria maculans 'brassicae' and related species and subspecies of the species complex

\begin{tabular}{|c|c|c|c|c|c|c|}
\hline \multirow[b]{2}{*}{ Leptosphaeria spp. } & \multirow[b]{2}{*}{ Geographical origin } & \multirow[b]{2}{*}{ Host plant sampled } & \multirow[b]{2}{*}{ Provider } & \multirow[b]{2}{*}{ Ref. $^{b}$} & \multicolumn{2}{|c|}{ Detection of $A v r L m \sigma^{a}$} \\
\hline & & & & & PCR & Southern \\
\hline \multicolumn{7}{|c|}{ L. maculans 'brassicae' } \\
\hline V23.1.3 & Laboratory isolate & $\ldots$ & M. H. Balesdent & 1 & + & + \\
\hline V29.3.1 & Laboratory isolate & $\ldots$ & M. H. Balesdent & 2 & - & - \\
\hline $\mathrm{Nz}-\mathrm{T} 4$ & New Zealand & $\ldots$ & S. Gowers & 2 & + & + \\
\hline IBCN18 & Australia & $\ldots$ & B. Howlett & 3 & - & - \\
\hline \multicolumn{7}{|l|}{ L. maculans 'lepidii' } \\
\hline IBCN84 & Canada & Lepidium sp. & G. Séguin-Swartz & 3 & - & - \\
\hline Lepi1 & Canada & Lepidium sp. & G. Séguin-Swartz & $\ldots$ & - & - \\
\hline Lepi2 & Canada & Lepidium sp. & G. Séguin-Swartz & 4 & - & - \\
\hline \multicolumn{7}{|c|}{ L. biglobosa 'brassicae' } \\
\hline B3.6 & France & Brassica juncea & H. Brun & 3 & - & nd \\
\hline IBCN10 & Germany & B. napus & H. H. Hoppe & 3 & - & - \\
\hline IBCN93 & United States & B. oleracea & P. H. Williams & 3 & - & - \\
\hline Gui2b3 & China & B. napus & J. S. West & 3 & - & nd \\
\hline \multicolumn{7}{|c|}{ L. biglobosa 'canadensis' } \\
\hline IBCN62 & Canada & Thlaspi arvense & G. Séguin-Swartz & 3 & - & - \\
\hline IBCN81 & Canada & B. napus & G. Séguin-Swartz & 3 & - & nd \\
\hline IBCN82 & Canada & B. juncea & G. Séguin-Swartz & 3 & - & - \\
\hline IBCN92 & Canada & B. rapa & P. H. Williams & 3 & - & nd \\
\hline \multicolumn{7}{|c|}{ L. biglobosa 'australensis' } \\
\hline IBCN29 & Australia & B. napus & B. Howlett & 3 & - & nd \\
\hline IBCN30 & Australia & B. napus & B. Howlett & 3 & - & - \\
\hline IBCN91 & United States & B. oleracea & P. H. Williams & 3 & - & - \\
\hline \multicolumn{7}{|l|}{ L. biglobosa 'thlaspii' } \\
\hline IBCN64 & Canada & T. arvense & G. Séguin-Swartz & 3 & - & - \\
\hline IBCN65 & Canada & T. arvense & G. Séguin-Swartz & 3 & - & - \\
\hline
\end{tabular}

${ }^{\text {a }} \mathrm{PCR}=$ polymerase chain reaction, $+=$ PCR amplification or Southern signal, $-=$ lack of amplification or hybridization, and nd $=$ experiment not done.

${ }^{\mathrm{b}}$ References: 1 = Balesdent et al. 2001, 2 = Balesdent et al. 2002, $3=$ Mendes-Pereira et al. 2003, and $4=$ Voigt et al. 2005. 
(Balesdent et al. 2002), was cloned following a lengthy chromosome walk. It was shown to share characteristics common to other fungal $A v r$ genes along with specific features. In common with most fungal Avr genes, AvrLml was shown to encode a
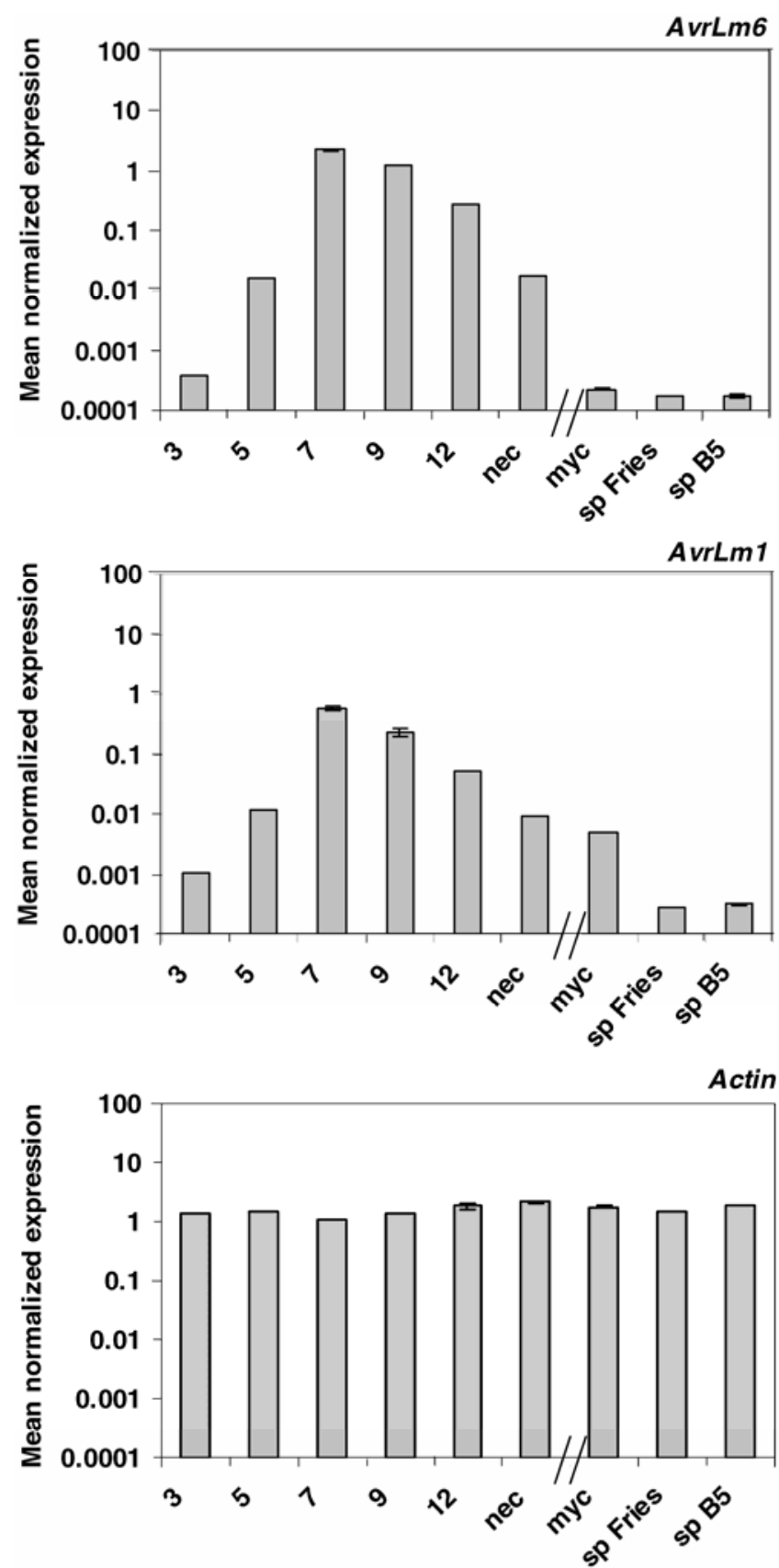

Fig. 3. Comparison of AvrLm1 and AvrLm6 expression during Leptosphaeria maculans in vitro growth and oilseed rape infection. Expression of avirulence genes was analyzed in the avirulent isolate v23.1.3 by quantitative reverse-transcription polymerase chain reaction (qRT-PCR). Number 3 to 12 = RT-PCR products obtained from RNA isolated from oilseed rape cotyledons (Westar) 3 to 12 days postinfection; nec = RT-PCR product obtained from RNA isolated from stem necrosis ( 2 months after infection); myc $=$ RT-PCR product obtained from RNA isolated from mycelial culture; $\mathrm{sp}=\mathrm{RT}-\mathrm{PCR}$ product obtained from RNA isolated from conidia germinating in rich medium (Fries) or under nitrogen starvation (B5). RNA extracted from uninfected cotyledons and water were used as negative controls. Gene expression levels are relative to $\beta$-tubulin. Actin is included to show that the calculated expression levels were not resulting from variations in the $\beta$-tubulin expression. Each data point is the average of two biological repeats (two extractions from different biological material) and two technical repeats (two RT-PCRs). Standard error of the mean normalized expression level is indicated by error bars. small secreted protein with no match in the databases. More specific traits included i) a low number of cysteine residues similar to other genes obtained following the use of map-based cloning strategies, but dissimilar to the Avr genes cloned in the related fungal species $C$. fulvum (Rivas and Thomas 2005); ii) a very specific genome environment characterized by the lack of other coding sequences within $269 \mathrm{~kb}$ and a strong suppression of meiotic recombination; and iii) constitutive expression leading the authors to conclude that AvrLml expression was not tightly regulated during plant infection (Gout et al. 2006).

In the present study, we undertook the cloning of a second gene of the AvrLm1-AvrLm2-AvrLm6 genetic cluster, AvrLm6. This enabled us to further investigate structural features of $A v r$ genes and their genome environment in L. maculans, the significance of the observed genetic clustering, and genome environment-dependent regulation of expression. In addition, RNAi analyses allowed us to perform preliminary investigations into dose-response effects of AvrLm6 induction of the Rlm6-mediated resistance.

\section{Structural traits and genome environment of AvrLm6.}

Identification of fungal and oomycete $A v r$ genes was in a few cases performed by "unbiased" methods, such as mapbased cloning and screening of cDNA libraries (Böhnert et al. 2004; Catanzariti et al. 2006; Farman et al. 2002; Orbach et al. 2000, Ridout et al. 2006); whereas in other models, such as $F$. oxysporum and $C$. fulvum, reverse genetics strategies were used (Rep et al. 2004; Rivas and Thomas 2005). In these latter cases, all Avr genes recovered were small, cysteine-rich proteins. This is consistent with the fact that these proteins, secreted in the apoplast or the plant vessels, have to resist plant proteases via the formation of disulfide bridges. Here, map-based cloning of AvrLm6 revealed structural features consistent with the L. maculans infection strategy and exemplary of $A v r$ genes that appear to be common to most filamentous fungi analyzed to date (i.e., small-secreted proteins, containing an even number of cysteine residues involved in disulphide bridge formation, with no matches in the databases) (Rep 2005). In addition, AvrLm6, like AvrLm1, is specific to the L. maculans subspecies 'brassicae', suggesting, as already suspected for other fungal $A v r$ genes, that $A v r$ genes are highly variable and rapidly evolving genes (Rep 2005). However, the structural features of AvrLm6 are quite different from those of the genetically closely linked AvrLm1. Actually, the putative secreted AvrLm1 protein is unable to form disulfide bonds, due to the presence of only one cysteine residue (Gout et al. 2006). Cysteine-poor Avr proteins were suggested to be common in biotrophic fungal or oomycete species for which the host plant-pathogen interface primarily consists of the closely associated haustorial and plant cell membranes (Ellis et al. 2006). Avr proteins are then suggested to be translocated into the plant cell cytoplasm by an unknown mechanism (Birch et al. 2006; Dodds et al. 2004). Therefore, unlike AvrLm6, AvrLm1 showed resemblance to Avr proteins produced at the haustorium-plant cell membrane interfaces, whereas L. maculans does not produce such specialized feeding structures. Thus, similarly to Melampsora lini, L. maculans is shown to be able to produce both cysteine-rich and cysteine-poor Avr proteins, whereas both genes are embedded in a similar, very specific genome environment.

The cloning of AvrLml highlighted a particular, isochore-like structure of the genomic region encompassing the gene. Isochores consist of long stretches of DNA that are homogeneous in base composition and compositionally correlated with the coding sequences that they embed (Bernardi 2000). Thus, the AvrLml genomic region showed a succession of small, GC- 
equilibrated regions (20 to $30 \mathrm{~kb}$ ) containing "housekeeping" genes and large AT-rich regions mainly containing noncoding sequences (LTR-retrotransposons) and AvrLml as a solo gene. Surprisingly, AvrLm6 was found here to mirror AvrLm1, with AvrLm6 also occurring as a solo gene within a $133-\mathrm{kb}$ noncod- ing region mainly containing LTR-retrotransposons. Thus, the AvrLm1-AvrLm6 genetic cluster actually corresponds to a large physical distance ( $230 \mathrm{~kb}$ separate AvrLmlfrom AvrLm6), but physical features of their genome environment condition a strong suppression of meiotic recombination around both

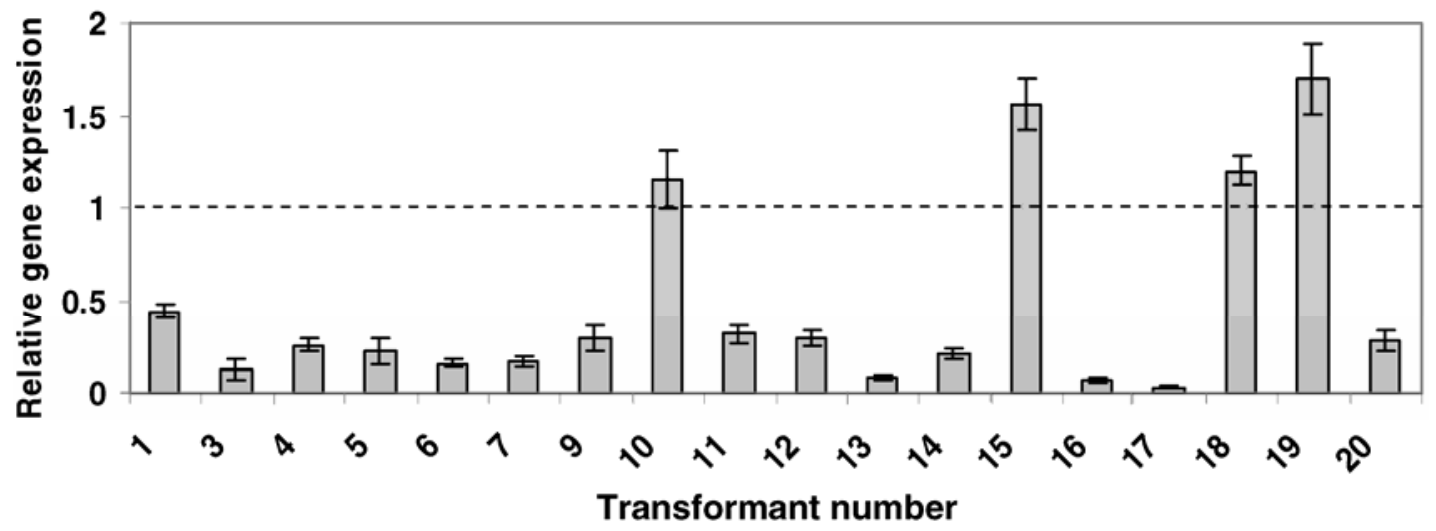

Fig. 4. Silencing of AvrLm6 expression by RNA interference: real-time reverse-transcription polymerase chain reaction analysis of AvrLm6 transcript accumulation in Leptosphaeria maculans AvrLm6-silenced transformants. Expression is relative to the $\beta$-tubulin expression level and to the expression of AvrLm6 in the wild-type isolate $\mathrm{v} 23.1 .3$ (2- $2^{-\Delta \Delta \mathrm{Ct}}$ method). The dashed line corresponds to the expression level of the wild-type isolate $\mathrm{v} 23.1 .3$.
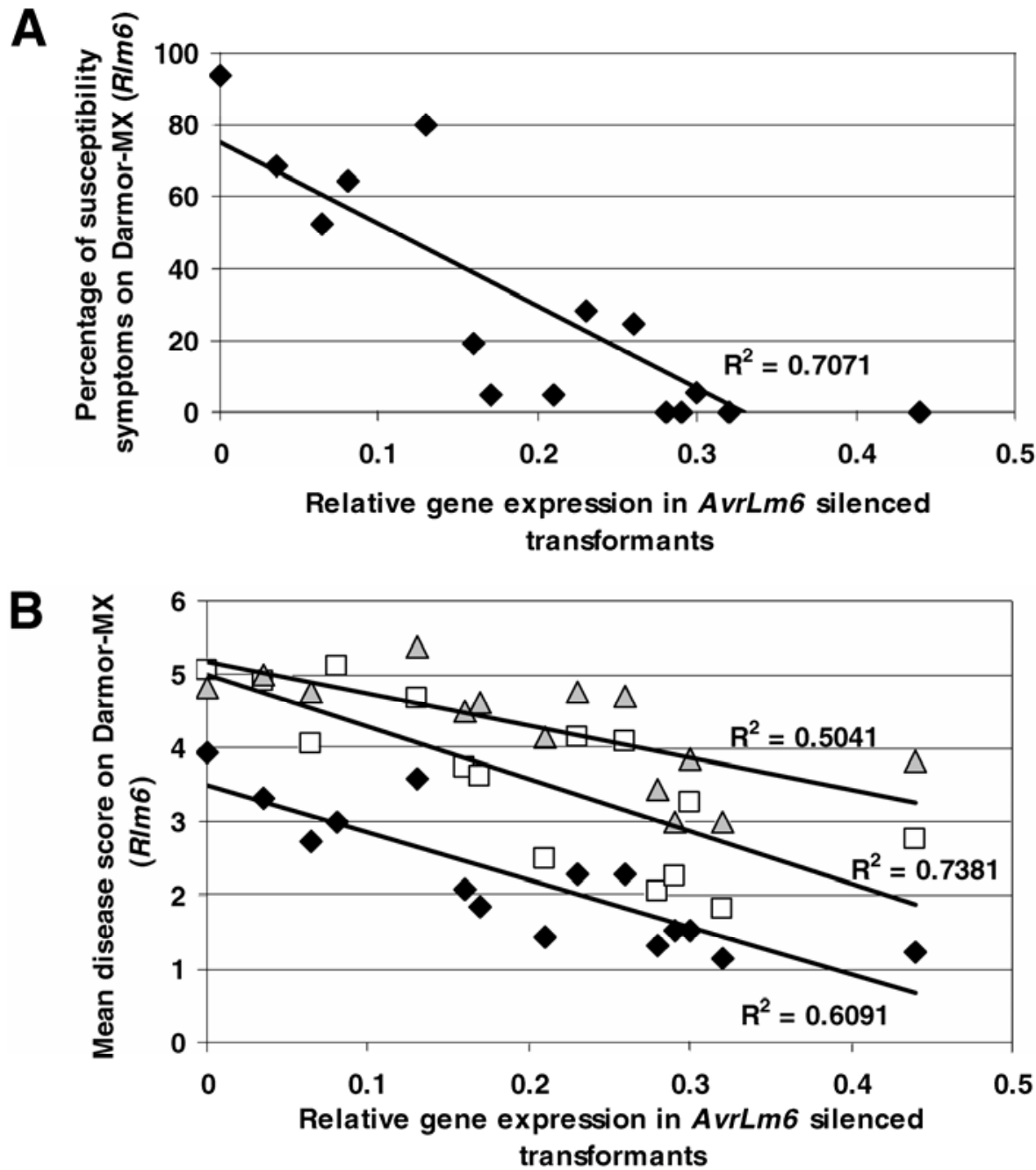

Fig. 5. Relationship between the level of expression of AvrLm6 and the symptoms expressed on Darmor-MX (Rlm6) after inoculation of silenced transformants (v23.1.3/pNAT1-AvrLm6), and of the v29.3.1 virulent isolate (relative gene expression $=0$ ). Results are expressed A, as the percentage of susceptibility lesions observed 14 days postinoculation (dpi) or $\mathbf{B}$, as the mean scoring using the IMASCORE rating scale comprising six infection classes (IC), where IC1 to IC3 corresponded to resistance and IC4 to IC6 to susceptibility (Balesdent et al. 2006). Symptoms were scored 14 (diamond), 18 (square), and = 21 (triangle) dpi. 
genes leading to this extreme distortion of genetic distance value. More surprisingly, whereas the average $\mathrm{G}+\mathrm{C}$ content of housekeeping genes in L. maculans is approximately $52 \%$, both AvrLm1 and AvrLm6, which show no homology at the nucleotide or amino acid levels, share a low $\mathrm{G}+\mathrm{C}$ content, mimicking that of their genome environment (Gout et al. 2006; this study). This feature is also uncommon for other fungal $A v r$ genes, except for the telomeric AVR-Pita gene of $M$. grisea (Orbach et al. 2000) and for the $A V R_{k l}$ paralogs of $B$. graminis f. sp. hordei that were located near retrotransposons (Ridout et al. 2006). However, comparisons with other fungal models are difficult to perform because there currently is no extensive information on the genome environment of $A v r$ genes in other fungal species. The most documented example is that of $M$. grisea, for which most of the Avr genes show no specific bias toward insertion into noncoding regions.

\section{Common regulation of $\boldsymbol{L}$. maculans avirulence genes?}

Fungal $A v r$ genes are always expressed during plant infection (Dodds et al. 2004; Laugé and de Wit 1998; Rep et al. 2004). For example, Avr2, Avr4, and Ecp2 from C. fulvum are expressed during the whole infection process (Laugé and de Wit 1998; Luderer et al. 2002), as are NIPl from $R$. secalis (Rohe et al. 1995) and AVR-Pita from M. grisea (Orbach et al. 2000). Indeed, the expression of these fungal Avr genes is not restricted to a specific stage of the infection process but is prevalent during colonization of host tissues. In contrast, the expression of some fungal $A v r$ genes can be localized to fungal structures specialized in plant penetration, such as appressoria of $M$. grisea, or in feeding, such as haustoria of Melampsora lini (Böhnert et al. 2004; Catanzariti et al. 2006; Dodds et al. 2004). Consistent with the lack of specific feeding or penetration organs in L. maculans, both RTPCR analysis of AvrLml timecourse expression (Gout et al. 2006) and qRT-PCR analysis of both AvrLm1 and AvrLm6 timecourse expression suggested an early induced expression of these genes upon plant infection and the maintenance of a high level of expression at very late stages of the plant tissue colonization (i.e., at the stem necrosis stage, 2 months after inoculation). Expression of fungal Avr genes also can be induced in specific culture conditions, such as nitrogen starvation (e.g., with the C. fulvum Avr9 expression regulated by the global nitrogen response factor NRF1) (Pérez-Garcia et al. 2001). However, Thomma and associates (2006) showed that expression of most $C$. fulvum effectors was not affected by varying levels of nitrogen supplementation in vitro and that the NRF1 nitrogen response regulator controlled only the Avr9 expression. Similarly here, although putative NIT2 binding sites were found in the promoter region of AvrLml and AvrLm6 (data not shown), there is no evidence that the expression of either gene is induced during nitrogen starvation.

Even though AvrLm1 and AvrLm6 are strongly expressed during plant infection, the RT-PCR data obtained by Gout and associates (2006) on AvrLml expression also suggested a constitutive expression of this gene, leading the authors to postulate that the particular genome environment of AvrLm1 prevented a tight regulation of gene expression. Here, qRTPCR analyses showed a very similar pattern of expression for both AvrLml and AvrLm6: a very low basal expression of both genes in germinating conidia; a rapid induction of expression $3 \mathrm{dpi}$, at a time when hyphae just begin to penetrate plant tissues; a strong increase of expression (with a level higher or similar to that of constitutively expressed $\beta$-tubulin) $7 \mathrm{dpi}$, at a time when a sheet of hyphae begin to colonize mesophyll tissues; and a moderate decrease of expression leading to maintenance of a high level of expression at very late stages of the disease. These data suggest a common regulation of expression of both $A v r$ genes, but they also are consistent with a tighter regulation of expression of AvrLm6 as compared with AvrLml, since AvrLml is maintained at a significant level of expression during regular mycelial growth in culture media. AvrLm1 and AvrLm6 are located as solo genes within regions showing structural features of heterochromatic regions which are, in general, less accessible to DNA binding and transcription factors (Grewal and Moazed 2003); therefore, it is tempting to postulate that specific regulators may control coexpression of genes in the AT-rich regions of the genome.

\section{RNA silencing, an efficient tool to study $A v r-R$ interactions in L. maculans.}

In contrast to the situation in plants and animals (Frantz 2003), RNA silencing has only recently been suggested as being a gene function exploratory tool in filamentous fungi (Nakayashiki 2005). RNA silencing has many advantages over gene disruption, including the generation of numerous transformants with different levels of target gene expression, the need to screen only a few transformants as compared with other targeting methods, and the efficiency to silence gene expression independently of the locus where the target gene is located. In L. maculans, knock-out strategies have been reported for a few genes (Gardiner and Howlett 2004; Idnurm et al. 2003; Wilson et al. 2002); however, they were found to be particularly inefficient, due to the need for large flanking homologous regions and for rare homologous recombination events. In the present study, AvrLm6 was found to be a unique coding sequence with flanking regions uniquely consisting of retrotransposons. With these retrotransposons being present in multiple locations within the genome, it would have been unfeasible to use homologous recombination strategies necessitating large flanking regions. Moreover, the AvrLm1-2-6 region was found to exhibit variable rates of recombination events, which were concentrated in the GCequilibrated regions and highly suppressed in the AT-rich regions. Finally, the region containing AvrLm6 shows structural features of a heterochromatin region, which generally are less accessible to targeted disruption than euchromatin regions (Grewal and Moazed 2003). RNA silencing was therefore the strategy of choice to study AvrLm6, and proved here to be efficient because the screening of only 18 transformants allowed us to recover 4 transformants showing a very low expression of AvrLm6 and a virulent phenotype on Rlm6 lines. This is, to our knowledge, the first report of RNA silencing of an Avr gene in fungi. RNAi analysis enabled us to evaluate the dose-response features of the Rlm6-mediated resistance, and showed that a level of AvrLm6 expression corresponding to $40 \%$ of that of the wild-type isolate is needed to consistently induce a resistance response. In addition, a linear relationship was found between increased levels of silencing and increased expression of symptoms. Further investigations into the correlation of AvrLm6 expression levels vs. quantity of AvrLm6 protein produced would help us to better interpret the symptoms observed on resistant cultivars.

Finally, one of the most intriguing questions raised during map-based cloning of both AvrLml and AvrLm6 concerns their isolation in the middle of large noncoding regions. The genome of $L$. maculans is currently considered as a mosaic of gene-rich, $\mathrm{G}+\mathrm{C}$-equilibrated regions and gene-poor, $\mathrm{A}+\mathrm{T}$ rich regions, which are present on all chromosomes. This genome is probably richer in repeats than most currently sequenced ascomycete genomess (Kuhn et al. 2006). On this basis, our current working hypothesis is that such gene-poor regions are specific "ecological niches" for effector genes in the genome of L. maculans. This will be evaluated in the 
near future during the ongoing map-based cloning of another $A v r$ gene cluster and through a systematic survey of genepoor regions in the L. maculans whole-genome sequence (Genoscope website).

\section{MATERIALS AND METHODS}

\section{Fungal isolates.}

Isolates of the L. maculans/L. biglobosa species complex used in this study were either collected from naturally infected crucifers or obtained following in vitro crosses (Table 2). The v23.1.3 isolate of L. maculans (AvrLm1-avrLm2-AvrLm6) (Balesdent et al. 2002) was used for the positional cloning of AvrLm6 (Attard et al. 2002) and the virulent isolate v29.3.1 (avrLm1-AvrLm2-avrLm6) (Balesdent et al. 2002) was used as a recipient isolate for genetic transformation and functional validation of the candidate genes. All fungal cultures were maintained on V8 juice agar medium and highly sporulating cultures were obtained on V8 juice as previously described (Ansan-Melayah et al. 1995).

\section{Plant inoculations.}

The interaction phenotypes (AvrLm6 or avrLm6) of L. maculans wild-type isolates and mutants (Table 1) were assessed following inoculation with $10 \mu \mathrm{l}$ of conidia suspensions $\left(10^{7}\right.$ conidia/ml $)$ on cotyledons of 15 -day-old plantlets of B. napus cv. Westar (susceptible control) and lines harboring the Rlm6 resistance gene (Darmor-MX and Falcon-MX). They also were inoculated onto $\mathrm{cv}$. Columbus carrying Rlm1 and cv. Bristol carrying Rlm2. These two resistance genes enable specific recognition of the $A v r$ genes $A v r L m 1$ and AvrLm2, respectively, genetically clustered with AvrLm6 (Balesdent et al. 2002). Plants were incubated in a growth chamber at 16 and $24^{\circ} \mathrm{C}$ (night and day, respectively) with a 12-h photoperiod. Symptoms were scored on 10 to 12 plants per interaction, 14 to 27 days after inoculation using the IMASCORE rating scale comprising six infection classes (ICs), where IC1 to IC3 corresponded to avirulent isolates (AvrLm) and IC4 to IC6 to virulent isolates (avrLm) (Balesdent et al. 2006). Mean disease scorings were calculated for each isolate/cultivar/scoring date combination and were analyzed using analysis of variance. Isolates or conditions were compared using a Fisher test $(\alpha=0.05)$. Transformants or conditions were compared to a control by a Dunnet multiple comparison test $(\alpha=0.05)$. All statistical analyses were performed using XLStat 7.5 software.

For timecourse studies of in planta $A v r$ gene expression, the second leaves of cv. Westar plantlets were inoculated using a conidial suspension of v23.1.3, as described for cotyledons, and sampling was performed at 3, 5, 7, 9, or 12 dpi. According to Balesdent and associates (1995), days 3 and 5 correspond to the initial colonization of leaf tissues with minute amounts of mycelium within the tissues, day 7 corresponds to the first detectable increase of the mycelial mass, and days 9 and 12 correspond to a dramatic increase of mycelium within the tissues, preceding the appearance of visible symptoms (100\% of plants with symptoms at approximately day 15). Stem lesions were also analyzed for $A v r$ gene expression. The junction of the second-leaf petiole and the stem of cv. Westar plantlets was punctured three times and inoculated with a $10-\mu 1$ droplet of $v 23.1 .3$ conidial suspension $\left(10^{7}\right.$ $\mathrm{ml}^{-1}$ ). Plants were incubated in the same growth chamber conditions as for inoculated cotyledons, and necrotic stem tissue was collected two months after inoculation. For silencing experiments, RNA was isolated from oilseed rape leaves infected with the wild-type isolate v23.1.3 and the different transformants 13 dpi. Although AvrLm6 expression does not reach its highest level at this timepoint, this stage was chosen because it corresponds to a large amount of mycelium within the plant tissues.

\section{DNA and RNA manipulations.}

For PCR, genomic DNA was extracted from conidia, using the DNeasy 96 Plant Kit (Qiagen S.A., Courtaboeuf, France) as described previously (Attard et al. 2002). Primer sequences used for the chromosome walk are shown in Supplementary Table S2. PCR amplifications were done in a total volume of $15 \mu \mathrm{l}$ containing $0.2 \mu \mathrm{M}$ each $\mathrm{dNTP}, 1.2 \mu \mathrm{M}$ each primer, 0.6 U of Taq DNA polymerase (Qbiogen, Illkirch, France), $1.5 \mu \mathrm{l}$ of $10 \times$ reaction buffer, and 10 to $30 \mathrm{ng}$ of genomic DNA. PCR amplifications were performed using an Eppendorf Mastercycler EP Gradient thermocycler (Eppendorf, Le Pecq, France). Sequencing was performed using a Beckman Coulter CEQ 8000 automated sequencer (Beckman Coulter, Fullerton, CA, U.S.A) according to the manufacturer's instructions. Procedures for gel electrophoresis, electrophoretic karyotyping, Southern blots, and hybridizations have been reported (Attard et al. 2005) and were adapted from procedures described by Sambrook and Russell (2001).

Total RNA was extracted from mycelium grown for one week in Fries liquid medium, from germinating conidia grown for $36 \mathrm{~h}$ in Fries or B5 minimal medium, and from infected leaf or stem tissues, using the TRIzol reagent (Invitrogen, Cergy Pontoise, France) according to the manufacturer's protocol. Total RNA was treated with DNase I RNase-Free (New England Biolabs, Ipswich, MA, U.S.A.). All samples, either corresponding to $100 \%$ fungal material or to infected plant tissues, were adjusted to $4 \mu \mathrm{g}$ of RNA and single-strand cDNA was generated using oligo-dT primed reverse transcription with PowerScript Reverse Transcriptase (Clontech, Palo Alto, CA, U.S.A.) according to the manufacturer's protocol.

\section{qRT-PCR.}

qRT-PCR was performed using model 7700 real-time PCR equipment (Applied Biosystems, Foster City, CA, U.S.A.) and ABsolute SYBR Green ROX dUTP Mix (ABgene, Courtaboeuf, France). For each condition tested, two RNA extractions from different biological samples and two reverse transcriptions for each biological repeat were performed. RNA extracted from uninfected leaves and water was used as negative controls. To determine the AvrLm6 expression level in silenced transformants, primers were designed to amplify a region of the AvrLm6 mRNA, AvrLm6-RTU being located within the AvrLm6 region targeted by the pNAT1-AvrLm6 vector and AvrLm6-RTL located in a region outside of the target sequence. A standard curve of amplification efficiency for $\beta$-tubulin, actin, AvrLm1, and AvrLm6 primers (Supplementary Table S2) was generated from purified RT-PCR products corresponding to 12-dpi-infected plant tissue across a three-orders-of-magnitude dilution series $\left(10^{-1}\right.$ to $10^{-3}$ dilutions). Samples were analyzed from a 10-fold dilution of the original RT products. Diluted RT products $(5 \mu \mathrm{l})$ were added to $12.5 \mu \mathrm{l}$ of PCR mix and $7.5 \mu \mathrm{l}$ of primers to a final concentration of $300 \mathrm{nM}$. The thermocycling profile consisted of an initial cycle of $50^{\circ} \mathrm{C}$ for $2 \mathrm{~min}$, a second cycle of $95^{\circ} \mathrm{C}$ for $15 \mathrm{~min}$, followed by 40 cycles of $95^{\circ} \mathrm{C}$ for $15 \mathrm{~s}$ and $60^{\circ} \mathrm{C}$ for $1 \mathrm{~min}$. The amplified product was detected every cycle at the end of the $60^{\circ} \mathrm{C}$ step. After the cycling, dissociation curve analysis confirmed the absence of nonspecific products in the reaction (temperature increase from 60 to $95^{\circ} \mathrm{C}$ in $20 \mathrm{~min}$ ). The fluorescence threshold $(\mathrm{Ct})$ value was determined at 0.1 of fluorescence intensity. $\mathrm{Ct}$ values were analyzed as described by Muller and associates (2002) for expression kinetic analysis or according to the $2^{-\Delta \Delta \mathrm{Ct}}$ method (Livak and Schmittgen 
2001) for silencing experiments. $\beta$-tubulin was used as a constitutive reference gene. For silencing experiments, results were reported to the $\mathrm{Ct}$ value of the wild-type isolate v23.1.3.

\section{Gene annotation.}

Annotations of UTRs, transcription start and stop sites, and intron positions were performed following PCR amplification and sequencing of $3^{\prime}$ and $5^{\prime}$ ends of cDNA using the GeneRacer kit (Invitrogen) and the Creator SMART cDNA library construction kit (Clontech) according to manufacturer's recommendation and using AvrLm6-1, AvrLm6-2, AvrLm6-nest1, and AvrLm6-nest2 (Supplementary Table S2) as specific primers.

\section{BAC libraries screening and chromosome walk.}

Construction of the v23.1.3 isolate genomic DNA HindIII and NdeII BAC libraries and screening strategies have been described previously (Attard et al. 2002, 2005; Gout et al. 2006). Markers were developed as described by Gout and associates (2006) and located on the v23.1.3 x v29.3.1 genetic cross (cross 34) (Balesdent et al. 2002; Gout et al. 2006) using the MapMaker/EXP version 3.0b software (available online; Whitehead/MIT Center for Genome Research, Cambridge, MA, U.S.A.) with a $\log$ of the likelihood ratio score of 4.0 and a maximum recombination frequency of $20 \mathrm{cM}$.

\section{BAC DNA sequencing and gene identification.}

End sequences of overlapping BAC clones or subclones identified in the course of the chromosome walk toward AvrLm6 were obtained as previously described (Attard et al. 2005). The BAC clones were fully sequenced, finished, and assembled at Genoscope as described by Gout and associates (2006).

Sequences were analyzed using the BLAST programs against the public databases of nucleotide and protein sequences, including the National Center for Biotechnology Information nonredundant databases and the COGEME database of phytopathogenic fungi, the annotated fungal genomes of $\mathrm{As}$ pergillus nidulans, $F$. graminearum, M. grisea, Neurospora crassa, S. nodorum, Ustilago maydis, and the available sequence releases of other fungal genomes (Fungal Genome Sequence Databases, Broad Institute Cambridge, MA, U.S.A.). Sequence analyses also were performed using the SignalP 3.0 program available online from the Center for Biological Sequence Analysis; the Isochore program to compute GC content (available online from the Institut Pasteur), which was set to a sliding window size of 3,500 bp and a shift increment of $100 \mathrm{bp}$; the pSORTII and SAPS softwares from the University of Tokyo and Stanford University (Palo Alto, CA, U.S.A.); the SCRATCH software available online from the School of Information and Computer Sciences; and by searches against the Pfam protein families database available online from Washington University in St. Louis. Two different gene-prediction programs also were used in combination to annotate the sequences of the AvrLm6 contig obtained. GENSCAN, available online from the Massachusetts Institute of Technology, was used with vertebrate and Arabidopsis settings and FGENESH from Softberry was set with $N$. crassa as the parameter matrix. Identifications of putative genes were based on the comparison of the outputs of these two programs because they use different gene-finding algorithms to predict gene structure, including exons, introns, promoter, and poly-adenylation signals.

Vector constructions and transformation of fungal isolates.

The binary vector $\mathrm{pBHt} 2$, which carries as a selectable marker the bacterial hygromycin B phosphotransferase gene, under the control of the Aspergillus nidulans trpC promoter, was used for Agrobacterium-mediated complementation of L. maculans.
pBHt2-LmCys 1 was obtained by digesting the BAC clone $20 \mathrm{H} 11$ with EcoRI and by ligating the BAC fragment from 12,271 to 15,841 bp into pBHt2 linearized with EcoRI. pBHt2LmCys 2 was obtained by digesting the BAC clone $6 \mathrm{H} 1$ with KpnI and BamHI. The KpnI/BamHI BAC fragment from 92,293 to $98,823 \mathrm{bp}$ was introduced into $\mathrm{pBHt} 2$ digested with $K p n I / B a m H I$. pBHt2-LmCys3 resulted from the amplification of BAC clone $64 \mathrm{D} 2$ with primers $64 \mathrm{D} 2-\mathrm{SmaU}$ and $\mathrm{L}$ that added SmaI digestion sites at the $5^{\prime}$ end of the PCR product. This product was digested with $S m a \mathrm{I}$ and was introduced into the SmaIdigested $\mathrm{pBHt} 2$. $\mathrm{pBHt} 2-\mathrm{LmMFS}$ resulted from a digestion of the BAC clone 33B11 with SnaBI and Eco47III. The BAC fragment from 28,128 to 37,327 bp was subcloned into pBluescript II, and the corresponding plasmid was digested with SacI. The SacI fragment corresponding to 31,015 to $37,327 \mathrm{bp}$ from BAC clone $33 \mathrm{~B} 11$ was introduced into the SacI-digested pBHt2.

Vector pNAT1-AvrLm6 was constructed for RNA-mediated gene silencing of AvrLm6, using the method described by Fitzgerald and associates (2004) with some modifications. Vector pJK11 (a gift from K. Plummer, Horticulture and Food Research Institute of New Zealand) was used for the construction of inverted repeats of the target gene AvrLm6. pJK11 consists of a backbone of pBluescript II containing the Glomerella cingulata gpdA promoter fragment and the Aspergillus nidulans $\operatorname{trp} C$ terminator fragment, separated by unique EcoRI and HindIII restriction sites. The hairpin inverted repeat fragments were created from the coding region of AvrLm6 by PCR, using primers described in Supplementary Table S2. The AvrLm6 sense fragment of the inverted repeat was amplified from cDNA of v23.1.3 mycelium using primers AvrLm6-Hind+ and AvrLm6-BamHI-. The sense product was digested with HindIII and BamHI. The antisense region was amplified with primers AvrLm6-BamHI+ and AvrLm6-EcoRI and was digested with BamHI and EcoRI. Sense and antisense fragments were ligated into an EcoRI-HindIII-digested pJK11. This expression cassette was excised by digestion with SpeI and XhoI. In contrast with the strategy of Fitzgerald and associates (2004), we did not use pJK1 as final binary vector, because it was found to be unstable after transformation into Agrobacterium tumefaciens $\mathrm{C} 58$. The binary vector pNAT1, which carries the nourseothricin acetyltransferase gene (NAT1) conferring resistance to the antibiotic nourseothricin (a gift from B. Howlett, University of Melbourne, Australia), was used for Agrobacteriummediated RNAi of $L$. maculans genes. The expression cassette was cloned into pNAT1 digested with SpeI and XhoI, creating the vector pNAT1-AvrLm6. The different constructs then were introduced into $A$. tumefaciens $\mathrm{C} 58$ by electroporation at 1.5 $\mathrm{kV}, 200 \mathrm{ohm}$, and $25 \mu \mathrm{F}$.

Transformation of L. maculans was performed as described by de Groot and associates (1998) with minor modifications (Gout et al. 2006). Fungal transformants were selected on hygromycin B at $200 \mu \mathrm{g} / \mathrm{ml}$ (Invitrogen) or nourseothricin at 50 $\mu \mathrm{g} / \mathrm{ml}$ (WERNER BioAgents, Jena, Germany).

\section{ACKNOWLEDGMENTS}

The authors wish to thank M. Chabirand, L. Coudard, and M Willigsecker (INRA PMDV, Versailles, France) for plant management; J. Roux and J. P. Narcy for management of transformants; and E. MendesPereira for assistance in sequencing. We are grateful to Y. Bertheau, A. Kobilinski, the MDO team, and A. Gioti (INRA, Versailles, France) for introduction to qRT-PCR experiments. We particularly thank K. Plummer (Horticulture and Food Research Institute of New Zealand, Auckland, New Zealand) for providing vector pJK11, used in RNAi experiments, B. Howlett (University of Melbourne, Australia) for providing vector pNAT1, and S. Fillinger (INRA, Versailles, France) for providing vector $\mathrm{pBHt} 2$. We also thank G. Séguin-Swartz (Agriculture and Agri-Food Canada, Saskatoon Research Centre, Canada) for providing the Canadian isolates Lepi1 and Lepi2, as well as $\mathrm{A}$. M. Chèvre and R. Delourme (INRA, 
Rennes, France) for providing the Falcon-MX and Darmor-MX lines. I. Fudal and S. Ross were funded by EU Contract QLK5-CT-2002-01813 'SECURE' and M. R. Eckert was funded by Marie-Curie Fellowship HPMT-CT-2001-00395 'FUNGENE.'

\section{LITERATURE CITED}

Ansan-Melayah, D., Balesdent, M. H., Buée, M., and Rouxel, T. 1995. Genetic characterization of AvrLml, the first avirulence gene of Leptosphaeria maculans. Phytopathology 85:1525-1529.

Attard, A., Gout, L., Gourgues, M., Kuhn, M. L., Schmit, J., Laroche, S., Ansan-Melayah, D., Billault, A., Cattolico, L., Balesdent, M. H., and Rouxel, T. 2002. Analysis of molecular markers genetically linked to the Leptosphaeria maculans avirulence gene AvrLm1 in field populations indicates a highly conserved event leading to virulence on RlmI genotypes. Mol. Plant-Microbe Interact. 15:672-682.

Attard, A., Gout, L., Ross, S., Parlange, F., Cattolico, L., Balesdent, M. H., and Rouxel, T. 2005. Truncated and RIP-degenerated copies of the LTR retrotransposon Pholy are clustered in a pericentromeric region of the Leptosphaeria maculans genome. Fungal Genet. Biol. 42:30-41.

Balesdent, M. H., Desthieux, I., Gall, C., Robin, P., and Rouxel, T. 1995. Quantification of Leptosphaeria maculans growth in cotyledons of Brassica napus using ELISA. J. Phytopathol. 143:65-73.

Balesdent, M. H., Attard, A., Ansan-Melayah, D., Delourme, R., Renard, M., and Rouxel, T. 2001. Genetic control and host range of avirulence toward Brassica napus cultivars Quinta and Jet Neuf in Leptosphaeria maculans. Phytopathology 91:70-76.

Balesdent, M. H., Attard, A., Kuhn, M. L., and Rouxel, T. 2002. New avirulence genes in the phytopathogenic fungus Leptosphaeria maculans. Phytopathology 92:1122-1133.

Balesdent, M. H., Barbetti, M. J., Li, H., Sivasithamparam, K., Gout, L., and Rouxel, T. 2005. Analysis of Leptosphaeria maculans race structure in a worldwide collection of isolates. Phytopathology 95:1061-1071.

Balesdent, M. H., Louvard, K., Pinochet, X., and Rouxel, T. 2006. A largescale survey of Leptosphaeria maculans occurring on oilseed rape in France. Eur. J. Plant Pathol. 114:53-65.

Bernardi, G. 2000. Isochores and the evolutionary genomics of vertebrates. Gene 241:3-17.

Birch, P. R. J., Rehmany, A. P., Pritchard, L., Kamoun, S., and Beynon, J. L. 2006. Trafficking arms: Oomycete effectors enter host plant cells. Trends Microbiol. 14:8-11

Böhnert, H. U., Fudal, I., Dioh, W., Tharreau, D., Notteghem, J. L., and Lebrun, M. H. 2004. A putative polyketide synthase peptide synthetase from Magnaporthe grisea signals pathogen attack to resistant rice. Plant Cell 16:2499-2513.

Catanzariti, A. M., Dodds, P., Lawrence, G. J., Ayliffe, M. A., and Ellis, J. G. 2006. Haustorially expressed secreted proteins from flax rust are highly enriched for avirulence elicitors. Plant Cell 18:243-256.

Chisholm, S. T., Coaker, G., Day, B., and Staskawicz, B. J. 2006. Hostmicrobe interactions: Shaping the evolution of the plant immune response. Cell 124:803-814.

de Groot, M. J. A., Bundock, P., Hooykaas, P. J. J., and Beijersbergen, A. G. M. 1998. Agrobacterium tumefaciens-mediated transformation of filamentous fungi. Biotechniques 16:839-842.

Dodds, P. N., Lawrence, G. J., Catanzariti, A.-M., Ayliffe, M. A., and Ellis, J. G. 2004. The Melampsora lini AvrL567 avirulence genes are expressed in haustoria and their products are recognized inside plant cells. Plant Cell 16:755-768.

Ellis, J., Catanzariti, A. M., and Dodds, P. 2006. The problem of how fungal and oomycetes avirulence proteins enter plant cells. Trends Plant Sci. 11(2):61-63.

Farman, M. L., Eto, Y., Nakao, T., Tosa, Y., Nakayashiki, H., Mayama, S., and Leong, S. A. 2002. Analysis of the structure of the AVR1-CO39 avirulence locus in virulent rice-infecting isolates of Magnaporthe grisea. Mol. Plant-Microbe Interact. 15:6-16.

Fitzgerald, A., van Kan, J. A. L., and Plummer, K. M. 2004. Simultaneous silencing of multiple genes in the apple scab fungus, Venturia inaequalis, by expression of RNA with chimeric inverted repeats. Fungal Genet. Biol. 41:963-971.

Flor, H. H. 1971. Current status of the gene-for-gene concept. Annu. Rev. Phytopathol. 9:275-296.

Frantz, S. 2003. Studies reveal potential pitfalls of RNAi. Nature Rev. 2:763-764.

Gardiner, D. M., and Howlett, B. J. 2004. Negative selection using thymidine kinase increases the efficiency of recovery of transformants with targeted genes in the filamentous fungus Leptosphaeria maculans. Curr. Genet. 45:249-255

Gout, L., Fudal, I., Kuhn, M. L., Blaise, F., Eckert, M., Cattolico, L., Balesdent, M. H., and Rouxel, T. 2006. Lost in the middle of nowhere:
The AvrLm1 avirulence gene of the dothideomycete Leptosphaeria maculans. Mol. Microbiol. 60:67-80.

Grewal, S. I. S., and Moazed, D. 2003. Heterochromatin and epigenetic control of gene expression. Science 301:798-802.

Hammond-Kosack, K. E., and Parker, J. E. 2003. Deciphering plant-pathogen communication: Fresh perspectives for molecular resistance breeding. Curr. Opin. Biotechnol. 14:177-193.

Idnurm, A., Warnecke, D. C., Heinz, E., and Howlett, B. J. 2003. Characterization of neutral trehalase and UDP-glucose: Sterol glucosyltransferase genes from the plant pathogenic fungus Leptosphaeria maculans. Physiol. Mol. Plant Pathol. 62:305-313.

Joosten, M. H., Cozijnsen, T. J., and De Wit, P. J. 1994. Host resistance to a fungal tomato pathogen lost by a single base-pair change in an avirulence gene. Nature 367:384-386.

Kamoun, S. 2006. A catalogue of the effector secretome of plant pathogenic oomycetes. Annu. Rev. Phytopathol. 44:41-60.

Keen, N. T. 1990. Gene-for-gene complementarity in plant-pathogen interactions. Annu. Rev. Genet. 24:447-463.

Kuhn, M. L., Gout, L., Howlett, B. J., Melayah, D., Meyer, M., Balesdent, M. H., and Rouxel, T. 2006. Genetic linkage maps and genomic organization in Leptosphaeria maculans. Eur. J. Plant Pathol. 114:17-31.

Laugé, R., and De Wit, P. J. 1998. Fungal avirulence genes: Structure and possible functions. Fungal Genet. Biol. 24:285-297.

Livak, K. J., and Schmittgen, T. D. 2001. Analysis of relative gene expression data using real-time quantitative PCR and the $2^{-\Delta \Delta C t}$ method. Methods 25:402-408.

Luderer, R., Takken, F. L. W., de Wit, P. J. G. M., and Joosten, M. H. A. J. 2002. Cladosporium fulvum overcomes $C f$-2-mediated resistance by producing truncated AVR2 elicitor proteins. Mol. Microbiol. 45:875-884.

Mendes-Pereira, E., Balesdent, M. H., Brun, H., and Rouxel, T. 2003. Molecular phylogeny of the Leptosphaeria maculans-L. biglobosa species complex. Mycol. Res. 107:1287-1304.

Mudgett, M. B. 2005. New insights to the function of phytopathogenic bacterial type III effectors in plants. Annu. Rev. Plant Biol. 56:509531.

Muller, P. Y., Janovjak, H., Miserez, A. R., and Dobbie, Z. 2002. Processing of gene expression data generated by quantitative real-time RTPCR. Biotechniques 32:1372-1378.

Nakayashiki, H. 2005. RNA silencing in fungi: Mechanisms and applications. FEBS (Fed. Eur. Biochem. Soc.) Lett. 579:5950-5957.

Nakayashiki, H., Hanada, S., Bao Quoc, N., Kadotani, N., Tosa, Y., and Mayama, S. 2005. RNA silencing as a tool for exploring gene function in ascomycete fungi. Fungal Genet. Biol. 42:275-283.

Orbach, M. J., Farrall, L., Sweigard, J. A., Chumley, F. G., and Valent, B. 2000. A telomeric avirulence gene determines efficacy for the rice blast resistance gene Pi-ta. Plant Cell 12:2019-2032.

Pérez-Garcia, A., Snoeijers, S. S., Joosten, M. H. A. J., Goosen, T., and de Wit, P. J. G. M. 2001. Expression of the avirulence gene Avr9 of the fungal tomato pathogen Cladosporium fulvum is regulated by the global nitrogen response factor NRF1. Mol. Plant-Microbe Interact. 14:316325.

Rep, M. 2005. Small proteins of plant-pathogenic fungi secreted during host colonization. FEMS (Fed. Eur. Microbiol. Soc.) Microbiol. Lett. 253:19-27.

Rep, M., van der Does, H. C., Meijer, M., van Wijk, R., Houterman, P. M., Dekker, H. L., de Koster, C. G., and Cornelissen, B. J. C. 2004. A small, cysteine-rich protein secreted by Fusarium oxysporum during colonization of xylem vessels is required for I-3-mediated resistance in tomato. Mol. Microbiol. 53:1373-1383.

Ridout, C. J., Skamnioti, P., Porritt, O., Sacristan, S., Jones, J. D. G., and Brown, J. K. M. 2006. Multiple avirulence paralogues in cereales powdery mildew fungi may contribute to parasite fitness and defeat of plant resistance. Plant Cell 18:2402-2414.

Rivas, S., and Thomas, C. M. 2005. Molecular interactions between tomato and the leaf mold pathogen Cladosporium fulvum. Annu. Rev. Phytopathol. 43:395-436.

Rohe, M., Gierlich, A., Hermann, H., Hahn, M., Schmidt, B., Rosahl, S., and Knogge, W. 1995. The race-specific elicitor, NIP1, from the barley pathogen, Rhynchosporium secalis, determines avirulence on host plants of the Rrs1 resistance genotype. EMBO (Eur. Mol. Biol. Organ.) J. 14:4168-4177.

Sambrook, J., and Russell, D. W. 2001. Molecular Cloning: A Laboratory Manual. Cold Spring Harbor Laboratory Press, Cold Spring Harbor, NY, U.S.A.

Thomma, B. P. H. J., Bolton, M. D., Clergeot, P. H., and de Wit, P. J. G. M. 2006. Nitrogen controls in planta expression of Cladosporium fulvum Avr9 but no other effector genes. Mol. Plant Pathol. 7:125-130.

Van Der Biezen, E. A., and Jones, J. D. G. 1998. Plant disease-resistance proteins and the gene-for-gene concept. Trends Biochem. Sci. 23:454-456.

Van Kan, J. A., van den Ackerveken, G. F., and de Wit, P. J. 1991. Cloning 
and characterization of cDNA of avirulence gene avr9 of the fungal pathogen Cladosporium fulvum, causal agent of tomato leaf mold. Mol. Plant-Microbe Interact. 4:52-59.

Voigt, K., Cozijnsen, A. J., Kroymann, J., Poggeler, S., and Howlett, B. J. 2005. Phylogenetic relationships between members of the crucifer pathogenic Leptosphaeria maculans species complex as shown by mating type (MAT1-2), actin, and $\beta$-tubulin sequences. Mol. Phylogenet. Evol. 37:541-557.

Westerink, N., Brandwagt, B. F., de Wit, P. J. G. M., and Joosten, M. H. A. J. 2004. Cladosporium fulvum circumvents the second functional resis- tance gene homologue at the $C f-4 \operatorname{locus}(H c r 9-4 E)$ by secretion of a stable avr4E isoform. Mol. Microbiol. 54:533-545.

Wilson, L. M., Idnurm, A., and Howlett, B. J. 2002. Characterization of a gene (sp1) encoding a secreted protein from Leptosphaeria maculans, the blackleg pathogen of Brassica napus. Mol. Plant Pathol. 3:487-493.

AUTHOR-RECOMMENDED INTERNET RESOURCE

Genoscope website: www.cns.fr 